\title{
O COMUNITARISMO E O NOVO CONSTITUCIONALISMO COMO BASES CONCILIADORAS DO SISTEMA PUNITIVO INDÍGENA E O ORDENAMENTO JURÍDICO BRASILEIRO
}

\author{
Lorena Alvarenga Costa* \\ Natália Meireles Borges **
}

\section{RESUMO}

O presente artigo tem como objetivo central analisar se a corrente comunitarista e o novo constitucionalismo latino-americano são bases teóricas eficazes para conciliar o sistema punitivo estatal e o sistema punitivo indígena. Para tanto, far-se-á uma breve apresentação das ideias e valores defendidos pelas referidas correntes, bem como uma exposição acerca do tratamento jurídico dos indígenas no ordenamento brasileiro, além de um estudo de caso no qual se evidenciou o conflito entre esses dois sistemas punitivos. Utilizou-se o método técnico-jurídico e o raciocínio hipotético-dedutivo, com técnicas de pesquisa doutrinária, legislativa e jurisprudencial.

PALAVRAS-CHAVE: Comunitarismo; Novo Constitucionalismo; Teorias da Justiça; Sistema Punitivo Indígena; Caso Denilson.

\section{THE COMMUNITARIAN POSITION AND THE NEW CONSTITUTIONALISM AS CONCILIATORY BASIS OF THE INDIGENOUS PUNITIVE SYSTEM AND THE BRAZILIAN LEGAL SYSTEM}

\begin{abstract}
The main objective of this article is to analyse if the communitarian position and the LatinAmerican new constitutionalism are effective theoretical basis for conciliating the indigenous punitive system and the state punitive system. To this end, there will be made a presentation of the ideas and values of those positions, as well as an exposition about the legal treatment of indigenous people in the Brazilian system, in addition to a case study in which the conflict between the aforementioned punitive systems was evidenced. The technical-legal method and hypothetical-deductive reasoning were used, with doctrinaire, legislative and jurisprudential research techniques.
\end{abstract}

KEYWORDS: Communitarian Position; New Constitutionalism; Theories of Justice; Indigenous Punitive System; Denilson Case.

\section{INTRODUÇÃO}

\footnotetext{
* Mestranda em Direito nas Relações Econômicas e Sociais pela Faculdade Milton Campos. Especialista em Direito Administrativo pela Universidade Cândido Mendes. Bacharela em Direito pela Universidade Federal de Juiz de Fora. Advogada. E-mail: lorena.alvarenga@hotmail.com.

${ }^{* *}$ Mestranda em Direito nas Relações Econômicas e Sociais pela Faculdade Milton Campos. Especialista em Direito de Empresa pela PUC Minas. Bacharela em Direito pela Faculdade Milton Campos. Advogada. E-mail: nataliameirelesborges@gmail.com.
} 
A comunidade indígena é um dos grupos marcantes do território brasileiro, com organização social, crenças, princípios, cultura e linguagem próprias de cada tribo. Dentro dessa diversidade, destaca-se o sistema punitivo indígena, que, no mesmo sentido, também possui suas particularidades, não se baseando nos princípios e regras do ordenamento jurídico pátrio.

Consequentemente, não raras vezes se observa a colisão entre o sistema punitivo indígena e o sistema punitivo estatal, não havendo, porém, critérios claros para se definir, no caso concreto, qual deles deverá prevalecer.

O comunitarismo, corrente de pensamento que defende a autonomia dos grupos, bem como o novo constitucionalismo latino-americano, teoria que defende que a Constituição deve servir de tradução fiel da vontade do povo, incluindo os diversos grupos que o compõe, surgem como bases que hipoteticamente podem ser utilizadas para essa definição.

Nesse sentido, o problema que o artigo enfrentará consiste justamente em definir se o comunitarismo e o novo constitucionalismo latino-americano são capazes de conciliar o sistema punitivo indígena e o ordenamento jurídico brasileiro.

O objetivo geral deste trabalho é analisar um caso concreto na jurisprudência pátria que exemplifica o conflito entre os dois sistemas punitivos, examinando a solução do caso apresentado sob o viés da corrente comunitarista e do novo constitucionalismo latinoamericano.

Como objetivos específicos se destacam: (i) a apresentação, no segundo capítulo deste artigo, das ideias e valores da corrente de pensamento comunitarista e do novo constitucionalismo latino-americano; (ii) no terceiro capítulo, a realização de uma breve exposição acerca do tratamento jurídico dos indígenas no ordenamento brasileiro; (iii) no quarto capítulo, a realização de um estudo de caso no qual se evidencia o conflito entre o sistema punitivo indígena e o estatal; e, por fim, (iv) a análise da decisão do caso exposto pela ótica do comunitarismo e do novo constitucionalismo.

Justifica-se este estudo na medida em que o Brasil, como país multiétnico, é composto por diversas comunidades, etnias e culturas, e, por isso, é corriqueira a colisão entre os valores e princípios desses grupos com o ordenamento jurídico pátrio, especialmente no que tange aos métodos e às normas aplicáveis na resolução de conflitos. 
O estudo terá como principais marcos teóricos a corrente comunitarista, capitaneada por filósofos como Michael Walzer e Charles Taylor, as lições de Roberto Viciano Pastor e de Rubén Martínez Dalmau acerca do fenômeno do novo constitucionalismo latino-americano, bem como a Lei $\mathrm{n}^{\mathrm{a}}$ 6.001, de 19 de dezembro de 1973 (Estatuto do Índio).

Utilizou-se o método técnico-jurídico e o raciocínio hipotético-dedutivo, mediante a realização de uma pesquisa na doutrina, legislação e jurisprudência nacional sobre o tema.

Concluiu-se pela confirmação da hipótese apresentada, sendo o comunitarismo e o novo constitucionalismo latino-americano bases eficazes para conciliar o ordenamento jurídico brasileiro com o sistema punitivo indígena, na medida em que permitem a máxima efetivação da justiça para a comunidade diretamente afetada.

\section{O COMUNITARISMO E O NOVO CONSTITUCIONALISMO LATINO- AMERICANO}

A corrente comunitarista, iniciada na América do Norte e capitaneada por filósofos como Michael Walzer e Charles Taylor, surgiu no contexto de um profundo debate teórico voltado à construção de uma sociedade mais justa, como contraposição à corrente liberal (TAVARES, 2014, p. 32).

Enquanto a corrente liberal acredita no universalismo, defendendo que a construção de uma sociedade justa passa pela escolha de princípios universais e imparciais, a corrente comunitarista sustenta a ideia do particularismo, defendendo que não existem indivíduos abstratos, tampouco princípios imparciais e aplicáveis de forma universal (TAVARES, 2014, p. 33).

Isto porque, conforme explica Felipe Cavaliere Tavares, para os comunitaristas não existem indivíduos livres de contingências históricas ou sociais, não sendo possível falar em justiça sem levar em consideração as raízes históricas e culturais de cada indivíduo e da comunidade em que ele está inserido:

Ao universalismo liberal, portanto, os comunitaristas opõem o particularismo, o individualismo, os valores da coletividade, ou seja, a autonomia pública se sobrepõe à autonomia privada. Desta forma, os comunitaristas entendem que justiça e pluralismo estão interligados pelo reconhecimento da multiplicidade de identidades sociais e culturas étnicas presentes na sociedade contemporânea, pelo reconhecimento das especificidades de cada ambiente social, enfim, pelos valores comunitários. 
(...)

Influenciados pelos ensinamentos de pensadores como Aristóteles, Hegel, Marx e Gramsci, os comunitaristas têm como tese central a necessidade de se entender o indivíduo como um membro inserido em uma determinada comunidade, influenciado sensivelmente, portanto, pelas raízes históricas e valores culturais desta comunidade. Ao dar prioridade à comunidade, portanto, o comunitarismo se opõe diretamente ao indivíduo abstrato, autônomo e racional do liberalismo, isolado de quaisquer raízes históricas ou influências socioculturais. (TAVARES, 2014, p. 33$350)$.

Pode-se dizer, com efeito, que a corrente comunitarista está intimamente relacionada à ideia de pluralismo, que, segundo Walzer, consiste na "diversidade de identidades sociais e de culturas étnicas e religiosas que estão presentes em qualquer sociedade moderna e complexa", se expressando "através de uma grande variedade de valores diferentes, incomensuráveis e incompatíveis defendidos por comunidades ou grupos distintos" (apud CITTADINO, 2004, p. 85-87).

Nesse sentido, para os comunitaristas, a construção de uma sociedade justa dependeria, necessariamente, do reconhecimento e da legitimação das diferenças, mediante a inclusão jurídica, social e econômica de todos os grupos que compõem determinada comunidade, respeitadas as suas particularidades.

Face ao pluralismo, portanto, não nos restaria outra alternativa "senão abdicar das respostas únicas, verdadeiras e definitivas para o problema da associação política e admitir o caráter parcial, incompleto e conflitivo do consenso entre indivíduos" (CITTADINO, 2004, p. 87).

Dessa forma, os comunitaristas defendem que não há uma solução universal e imparcial para os conflitos de interesse, justamente em razão da diversidade de identidades sociais e culturais. Com efeito, nenhum ordenamento jurídico seria capaz, por meio da previsão de normas abstratas e aplicáveis de forma universal, de alcançar uma solução justa para os conflitos envolvendo todos os diferentes grupos que compõem aquela comunidade, sendo necessária, para tanto, a criação de mecanismos jurídicos que reconheçam e legitimem a normatividade própria de cada um desses grupos.

Embora a corrente comunitarista tenha ganhado bastante reconhecimento na América do Norte, o mesmo não ocorreu no Brasil. Em verdade, na América Latina como um todo, não houve um caloroso debate teórico entre liberais e comunitaristas (TAVARES, 2014, p. 34). Não obstante, pode-se dizer que os valores defendidos pelos comunitaristas foram 
parcialmente alcançados por meio do fenômeno denominado novo constitucionalismo latinoamericano, que será explicado adiante.

Segundo Roberto Viciano Pastor e Rubén Martínez Dalmau, o novo constitucionalismo tem como preocupação não apenas a dimensão jurídica da Constituição (e a sua normatividade), mas também a sua legitimidade democrática. Desta forma, para esse movimento, o primeiro problema do constitucionalismo democrático seria "servir de tradução fiel da vontade constituinte do povo" (PASTOR; DALMAU, 2011, p. 07).

Ainda de acordo com os autores, o novo constitucionalismo é, principalmente, "uma teoria (democrática) da Constituição", teoria esta que se converteu em prática na América Latina através dos processos constituintes efetivamente democráticos ocorridos a partir da década de noventa, que foram "articulados mediante a convocação de uma Assembleia Constituinte e a ratificação popular direta do texto constitucional”. Por meio desses processos constituintes:

Foram legitimadas constituições que buscaram (...) revolucionar o status quo das sociedades em condições de necessidade. (...) Um constitucionalismo que possa romper com o que se considera imutável, e que possa avançar no caminho da justiça social, da igualdade e do bem-estar dos cidadãos. (tradução nossa) (PASTOR; DALMAU, 2011, p. 08).

Reflexo disso são os elementos materiais comuns das Constituições promulgadas no contexto do novo constitucionalismo latino-americano, quais sejam: (i) compromisso constitucional com a promoção da participação popular, a partir da criação de mecanismos de democracia participativa; (ii) preocupação com a superação das desigualdades sociais e econômicas; (iii) existência de um extenso rol direitos, não se preocupando as novas Constituições apenas com o estabelecimento de direitos de forma genérica, mas também com a criação de direitos específicos para os diferentes grupos (mulheres, idosos, indígenas, crianças, dentre outros); e (iv) integração dos setores marginalizados historicamente, como é o caso dos povos indígenas (PASTOR; DALMAU, 2011, p. 20-24).

Assim como no comunitarismo, há no novo constitucionalismo latino-americano, por conseguinte, uma evidente preocupação com a inclusão dos valores e ideais de todos os grupos que compõem aquela sociedade no texto constitucional e, não menos importante, de se respeitar a normatividade daquele grupo dentro do Estado. 
Portanto, o comunitarismo e o novo constitucionalismo latino-americano têm em comum o reconhecimento da importância das comunidades e a necessidade do respeito aos valores e tradições de cada grupo, defendendo um pluralismo jurídico para uma sociedade justa.

Nesse contexto, para aqueles que defendem a ideia de pluralismo jurídico, o Estado não seria a fonte única e exclusiva do direito. Além da legislação formal do Estado, também seria fundamental o reconhecimento de práticas autônomas de elaboração legal comunitária (WALKMER, 2015, p. 199). Teríamos, assim, diversas fontes jurídicas, em respeito aos valores das diferentes comunidades que compõem aquele Estado. A nação seria uma aliança de diferentes grupos, sendo, nesse caso, permitido que cada um deles solucionasse internamente seus conflitos de interesse, de acordo com as normas e princípios aprovados por um consenso interno.

Dentre todas as novas constituições latino-americanas, a que representou uma mudança mais radical e que mostra esses elementos materiais de forma mais evidente, especialmente no que tange à integração dos indígenas, é, sem dúvidas, a Constituição boliviana.

Referida Constituição, na mesma linha do que defende o comunitarismo, tem como principal premissa o pluralismo, ou seja, o reconhecimento de que o povo boliviano é de composição plural, desde suas origens. É o que se depreende do seu preâmbulo:

Nós povoamos esta Mãe sagrada Terra com faces diferentes, e desde então entendemos a pluralidade prevalecente de todas as coisas e nossa diversidade como seres e culturas. É assim que conformamos nossos povos, e nunca havíamos entendido o racismo até que o sofremos desde os tempos sombrios da colônia.

(...) O povo boliviano, de composição plural, desde as profundezas da história, inspirado nas lutas do passado, no levante indígena anticolonial, na independência, nas lutas populares de libertação, nas marchas indígenas, sociais e sindicais, nas guerras da água e de outubro, nas lutas pela terra e território, e com a memória dos seus mártires, constrói um novo Estado. (ESTADO PLURINACIONAL DA BOLÍVIA, 2009, [documento eletrônico]).

O reconhecimento do pluralismo como o principal fundamento da Constituição boliviana teve como consequência não apenas a concessão de direitos específicos aos indígenas, tal como ocorreu nas demais Constituições latino-americanas, mas também, de forma inovadora, o reconhecimento de um pluralismo jurídico, mediante a criação de um 
sistema em que coexistem duas jurisdições distintas, independentes e de mesma hierarquia: a jurisdição ordinária e a jurisdição originária, indígena ou campesina.

A jurisdição indígena originária é exercida pelos povos e nações indígenas originários bolivianos, por meio da aplicação dos seus princípios, valores, normas e procedimentos próprios. Referida jurisdição se aplica apenas aos membros da respectiva nação ou povo indígena originário e às relações e fatos jurídicos que se realizam ou cujos efeitos se produzam dentro daquela comunidade.

No entanto, as decisões proferidas no âmbito da jurisdição indígena originária não podem ser questionadas ou revistas pela jurisdição ordinária boliviana, cabendo a todas as autoridades e pessoas acatá-las.

Segundo Raquel Yrigoyen Fajardo, a Constituição Boliviana seria uma das mais "evoluídas" dentre todas as Constituições promulgadas no contexto do novo constitucionalismo latino-americano, uma vez que enquadrada no ciclo mais avançado das reformas constitucionais. Para a autora (apud FILHO, 2016, p. 78-79):

\begin{abstract}
o primeiro ciclo seria o constitucionalismo multicultural (1982/1988), que introduz o conceito de diversidade cultural e reconhece direitos indígenas específicos. (...) O segundo ciclo é marcado pelo constitucionalismo participativo e pluralista, que segundo Wolkmer (2011, p. 403) tem seu auge na Constituição Venezuelana de 1999. Fajardo (2011, p. 142) nomeia de constitucionalismo pluricultural (1988/2005), e abarca conceitos de nação multiétnica e Estado pluricultural, prevê amplo catálogo de direitos indígenas e outros coletivos étnicos, bastante influenciado pelos princípios que decorreram da Convenção 169/OIT. (...) O terceiro e, por enquanto, o último ciclo, marcado pelo caráter revolucionário das Constituições do Equador (2008) e da Bolívia (2009), seria o constitucionalismo plurinacional (2006-2009) ou, nas palavras de Wolkmer (ibid.) se constitui como um "constitucionalismo plurinacional comunitário".
\end{abstract}

No Brasil, assim como na Bolívia, a comunidade indígena é extremamente marcante, possuindo valores, costumes, crenças e tradições díspares da maior parte da população brasileira.

Porém, ao contrário do país vizinho, o Brasil ainda não alcançou o terceiro ciclo do constitucionalismo, não havendo, no nosso ordenamento, uma ideia de plurinacionalidade, tampouco de pluralismo jurídico. No Brasil, portanto, a jurisdição é única, não se excluindo da competência do Poder Judiciário estatal, por exemplo, a análise das infrações cometidas por membros das comunidades indígenas, o que, logicamente, pode gerar divergências, conforme será demonstrado adiante. 


\title{
3 A COMUNIDADE INDÍGENA NO ORDENAMENTO JURÍDICO BRASILEIRO
}

A principal lei que trata da situação jurídica dos índios e da comunidade indígena no Brasil é a Lei no 6.001, de 19 de dezembro de 1973 (Estatuto do Índio). Referida lei, embora reconheça importantes direitos aos indígenas, é considerada bastante retrógrada, na medida em que possui como propósito a integração progressiva dos índios à comunhão nacional.

O objetivo exposto no Estatuto do Índio reforça a errônea ideia de que o indígena seria um ser inferior, em estágio atrasado de desenvolvimento, e que precisaria, portanto, passar por um processo gradual de integração à "sociedade civilizada". Conforme explica Walter Claudius Rothenburg:

\begin{abstract}
Quanto aos índios, prevaleceu até aqui, na história, a perspectiva de integração à sociedade envolvente. O índio, visto a partir dessa "sociedade envolvente" (em que o adjetivo "envolvente" passa uma idéia "tentacular", daquilo que envolve, sufoca, absorve) e segundo uma concepção evolucionista da humanidade calcada em padrões ocidentais capitalistas (burgueses), é considerado residente em estágios primitivos de desenvolvimento. A sociedade envolvente, por outro lado, representaria o mais elevado patamar de civilização e o único caminho de emancipação definitiva dos primitivos. Uma integração em tais moldes tenderia a provocar o desaparecimento cultural dos povos considerados mais atrasados. "Nesta perspectiva, portanto [anota Helder Girão Barreto (2004:34)], o índio é visto como um 'ser inferior' que deve e precisa ser 'integrado à comunhão nacional'. Completada a integração, não será mais considerado 'inferior', mas também não será mais considerado índio e, portanto, não merecerá mais qualquer forma de tutela especial" (ROTHENBURG, 2007, p. 286).
\end{abstract}

Foi apenas com a Constituição Federal de 1988 que se passou a reconhecer ao indígena o "direito de ser índio" e de "manter-se como índio, com sua organização social, costumes, línguas, crenças e tradições", de acordo com o artigo 231 da Magna Carta (ROTHENBURG, 2007, p. 286). Na linha das demais constituições promulgadas no contexto do novo constitucionalismo latino-americano, a Constituição Federal de 1988 dedicou aos índios um capítulo específico, além de assegurar a proteção da manifestação da cultura indígena (artigo 215, da Constituição Federal de 1988).

Não obstante o caráter retrógrado do Estatuto do Índio, anterior à Constituição Federal de 1988 mas ainda vigente, cumpre ressaltar a sua importante contribuição no que tange à autonomia dos povos indígenas, ao dispor, em seu artigo 57, in verbis:

Será tolerada a aplicação, pelos grupos tribais, de acordo com as instituições próprias, de sanções penais ou disciplinares contra os seus membros, desde que não 
revistam caráter cruel ou infamante, proibida em qualquer caso a pena de morte (BRASIL, 1973).

A tolerância à aplicação de sanções pelos próprios grupos indígenas não exclui em absoluto, porém, a possibilidade de aplicação das sanções penais pelo Estado. Tanto é verdade que o artigo 56 da mesma Lei dispõe que, no caso de condenação de índio por infração penal, a pena deverá ser atenuada e na sua aplicação o juiz atenderá também ao grau de integração do silvícola. No mesmo sentido, cita-se a Súmula no 140 do Superior Tribunal de Justiça, que atribui à Justiça Comum Estadual a competência para julgamento de crime em que o indígena figure como autor ou vítima.

Consequência disso são os recorrentes conflitos entre as normas jurídicas postas pelo Estado e as sanções aplicadas no âmbito das comunidades indígenas, tal como ocorreu no caso envolvendo o índio Denilson Trindade, que será analisado a seguir.

\section{ANÁLISE DA JURISPRUDÊNCIA BRASILEIRA: CASO DENILSON TRINDADE DOUGLAS}

Um caso emblemático da jurisprudência pátria, no qual é possível constatar o conflito entre ordenamento jurídico brasileiro e o sistema punitivo indígena ocorreu no estado de Roraima.

No dia 20 de junho de 2009, na comunidade indígena do Manoá/Pium, região Serra da Lua, município de Bonfim, o indígena Denilson Trindade Douglas, sob o efeito de bebida alcoólica, desferiu diversas facadas contra o seu irmão, o indígena Alanderson Trindade Douglas, levando-o a óbito (RORAIMA, 2015, [documento eletrônico]).

Logo após o delito e antes de qualquer denúncia formal, no dia 26 de junho de 2009, os chefes da tribo, chamados de Tuxuaus, se reuniram com os membros do conselho da comunidade indígena do Manoá, com o intuito de deliberar uma eventual punição ao indígena.

Para tanto, realizaram a oitiva do "acusado" e de "testemunhas", concluindo pela imposição de várias sanções, em especial, a construção de uma casa para a esposa da vítima e a proibição do "acusado" de se ausentar da comunidade do Manoá sem permissão dos Tuxuaus. 
Anos após, em 06 de abril de 2013, reuniram-se os líderes de várias comunidades indígenas (Anauá, Manoá, Wai Wai, entre outras), e, neste momento, determinaram mais sanções ao indígena Denilson, quais sejam:

1. Deixar a comunidade do Manoá e cumprir pena na região da tribo Wai Wai por 05 (cinco) anos, com possibilidade de redução conforme seu comportamento;

2. Cumprir o Regimento Interno do Povo Wai Wai, respeitando a convivência, o costume, a tradição e moradia junto ao povo Wai Wai;

3. Participar de trabalho comunitário;

4. Participar de reuniões e demais eventos desenvolvidos pela comunidade;

5. Não comercializar nenhum tipo de produto, peixe ou coisas existentes na comunidade sem permissão da comunidade juntamente com Tuxaua;

6. Não desautorizar o Tuxaua, cometendo coisas às escondidas sem conhecimento dele;

7. Ter terra para trabalhar, sempre com conhecimento e na companhia do tuxaua;

8. Aprender a cultura e a língua Wai Wai. (RORAIMA, 2015, [documento eletrônico])

Salienta-se que dentre as penalidades aplicadas pela comunidade indígena não se incluiu a privação da liberdade. Isto porque, até mesmo em relação às cominações, constata-se a primazia do benefício comunitário, visto que nas penas há uma ênfase e preferência à participação social, cultural e ao trabalho.

$\mathrm{Na}$ visão da comunidade indígena, a privação da liberdade através da reclusão do acusado é considerada como perda de força de trabalho para toda a comunidade (LOPES; UCHOA, 2018, p.11-30). Assim, o indígena que cometeu um ato reprovável, para reparar seu erro, deve servir a todo o grupo, seja trabalhando, seja participando social e culturalmente, ou, ainda, aprendendo a respeitar as tradições locais, de forma que, ao final, a comunidade indígena seja beneficiada de alguma forma.

Com efeito, pelo fato do indígena Denilson ter matado seu irmão, foram aplicadas uma série de penalidades, primeiramente pelas autoridades de sua própria tribo e, em seguida, pela deliberação em conjunto das autoridades de várias comunidades indígenas, de acordo com a tradição e costumes dos grupos indígenas envolvidos.

É importante observar, também, que as penalidades impostas pelo tribunal indígena não violaram o ideal de aprimoramento humano, uma vez que não houve a aplicação de penas cruéis ou contrárias ao princípio da dignidade humana (LOPES; UCHOA, 2018, p.11-30).

Contudo, analisando o fato sob a ótica da legislação brasileira, é evidente que a conduta do indígena Denilson se enquadra perfeitamente no tipo penal do artigo 121 do Código Penal Brasileiro, vez que o acusado dolosamente tirou a vida de outro ser humano, de 
forma comissiva, com um auxílio de um instrumento ofensivo, conduta que é punida com pena de reclusão.

Assim, após ter ciência do fato, em fevereiro de 2012, o Ministério Público de Roraima ofereceu denúncia, na qual apontava que o indígena Denilson teria cometido homicídio qualificado, nos termos do artigo $121, \S 2^{\circ}$, inciso II do Código Penal Brasileiro, o que deu ensejo à ação penal $\mathrm{n}^{0}$ 0090.10.000302-0 (RORAIMA, 2013, [documento eletrônico]).

A defesa do acusado alegou, em suma, a incompetência do Juízo, vez que o fato já teria sido julgado pela comunidade indígena, da qual o acusado fazia parte e, além disso, que o indígena já estava cumprindo as penalidades impostas e que, por isso, não poderia responder novamente pelo mesmo fato, em respeito ao princípio do non bis in idem.

Ancorou seus argumentos no artigo 57 do Estatuto do Índio (lei 6.001/1973), o qual traria uma vedação implícita à punição dupla, e, além disso, no artigo 9 da Convenção 169 da OIT, que afastaria a aplicação da lei penal ao caso.

Ao revés, o Ministério Público afirmava que, em virtude do monopólio do direito de punir estatal, não existiria dupla punição e que, ainda, por se tratar de crime comum, também não haveria incompetência do Juízo.

Em setembro de 2013, foi prolatada a sentença, na qual o juiz de primeira instância, primeiramente, distinguiu as situações nas quais o Estado poderia investigar, processar e julgar um indígena, a depender da existência ou não de prévio julgamento pela tribo. Nesse sentido, definiu que, nos casos em que acusado e vítima são índios e o fato ocorreu em terras indígenas, se:

i. Não há julgamento do fato pela comunidade indígena: o Estado deterá o direito de punir e atuará apenas de forma subsidiária;

ii. Há julgamento do fato pela comunidade indígena: o Estado não terá o direito de punir (RORAIMA, 2013, [documento eletrônico]).

Segundo a decisão, o artigo 57 do Estatuto do Índio seria uma exceção ao direito de punir do Estado, na medida em que determina o respeito aos usos e costumes indígenas. Também fundamentou sua decisão no artigo 231 da Constituição Federal, no artigo $6^{\circ}$ do Estatuto do Índio e no artigo 9 da Convenção 169 da OIT.

Assim, em uma decisão inédita, o magistrado não apreciou o mérito da denúncia em desfavor do indígena Denilson, com fundamento na ausência do direito de punir do Estado, 
em razão de o acusado e a vítima serem indígenas, o fato ter ocorrido em terras indígenas e a tribo, à qual pertence o acusado, já ter julgado o fato e aplicado sanções.

Em seguida, a acusação interpôs apelação, na qual o Tribunal de Justiça de Roraima manteve a decisão da sentença proferida no juízo a quo, porém sob fundamentos diferentes.

No acórdão, a Turma entendeu que o caso seria solucionado com base no princípio do non bis idem, segundo o qual o indivíduo não poderia ser punido mais de uma vez pelo mesmo fato, seja qual for o ente que o pune, sendo uma garantia processual penal ampla do indivíduo. Ademais, a decisão de segunda instância também se ancorou no artigo 8 da Convenção Americana de Direitos Humanos, artigo 57 do Estatuto do Índio e artigo 9 da Convenção da OIT (RORAIMA, 2015, [documento eletrônico]).

Reconheceu a Justiça brasileira, portanto, a autonomia tribal, respeitando o julgamento da comunidade indígena, que foi realizado de acordo com os seus costumes e tradições, se abstendo o Estado de aplicar a legislação penal para um crime doloso contra a vida praticado dentro do território brasileiro.

\section{O COMUNITARISMO E O NOVO CONSTITUCIONALISMO LATINO- AMERICANO COMO BASES CONCILIADORAS}

Em análise do caso do indígena Denilson, fica evidente a relação entre os fundamentos da decisão e o pensamento comunitarista e do novo constitucionalismo latinoamericano, visto que, na solução do conflito de interesse, existiu uma primazia da autonomia da comunidade indígena, em detrimento da aplicação da lei brasileira, em que pese o desfecho e as sanções aplicadas pelo tribunal indígena serem totalmente distintas das previstas na legislação penal.

$\mathrm{Na}$ verdade, a decisão claramente considerou que, em razão da diversidade de valores, costumes e crenças dos povos indígenas, a aplicação da lei penal brasileira, da maneira convencional, poderia não surtir efeitos positivos perante a comunidade afetada.

Isto porque, como elucidado anteriormente, para a comunidade indígena, o agressor deve reparar seu erro por meio de ações em benefício direto da comunidade e da vítima. Assim, a reclusão do acusado em uma penitenciária, com a privação de sua liberdade, apenas significaria uma perda de força de trabalho para a comunidade, sendo uma medida insatisfatória e prejudicial para aquele grupo. 
Com efeito, a punição penal pelo Estado não seria considerada justa e, se assim ocorresse, provavelmente a dívida do ofensor perante a sua comunidade permaneceria incólume. Além disso, a retirada do indígena da sua comunidade e a sua transferência para uma penitenciária consistiria em um grande impacto cultural, o que, seguramente, dificultaria sua ressocialização à tribo indígena.

Fica claro que a aplicação da sanção penal pelo Estado, portanto, além de não atingir todos os seus objetivos perante ao acusado, não seria benéfica à comunidade indígena, afetada diretamente pelo crime.

Ademais, as penalidades impostas pelo tribunal indígena respeitaram a dignidade do ser humano, sem aplicação de penas cruéis, de morte ou de tortura, abomináveis para o ordenamento jurídico brasileiro.

Em razão da diversidade de culturas, o pensamento comunitarista e o novo constitucionalismo latino-americano compreendem que não é possível uma solução universal para todos os conflitos de interesse, sendo fundamental analisar a comunidade afetada e seus princípios morais, para que se alcance a melhor solução naquela situação específica.

No caso Denilson, na mesma linha do que defendem essas correntes de pensamento, o judiciário brasileiro foi capaz de conciliar suas normas com os costumes indígenas, se abstendo de interferir na solução daquele conflito, respeitando a normatividade da comunidade, e, consequentemente, alcançando a solução mais justa e coerente para aquele grupo específico.

\section{CONCLUSÃO}

Em contraposição à corrente liberal, que acredita no universalismo, a corrente comunitarista sustenta a ideia do particularismo, defendendo que não existem indivíduos abstratos, tampouco princípios imparciais e aplicáveis de forma universal.

Para o comunitarismo, portanto, a construção de uma sociedade justa dependeria, necessariamente, do reconhecimento e da legitimação das diferenças, mediante a inclusão jurídica, social e econômica de todos os grupos que compõem determinada comunidade, respeitadas as suas particularidades.

Embora a corrente comunitarista tenha ganhado bastante reconhecimento na América do Norte, o mesmo não ocorreu na América Latina. Não obstante, pode-se dizer que os 
valores defendidos pelos comunitaristas foram parcialmente alcançados por meio do fenômeno denominado novo constitucionalismo latino-americano, teoria que se converteu em prática a partir da década de noventa e que defende que a Constituição deve servir de tradução fiel da vontade do povo, incluindo os diversos grupos que o compõe.

No Brasil, a principal lei que trata da situação jurídica do índio é a Lei n 6.001 , de 19 de dezembro de 1973 (Estatuto do Índio). Não obstante o caráter retrógrado da referida Lei, cumpre ressaltar a sua importante contribuição no que tange à autonomia dos povos indígenas, ao dispor, em seu artigo 57, que "será tolerada a aplicação, pelos grupos tribais, de acordo com as instituições próprias, de sanções penais ou disciplinares contra os seus membros, desde que não revistam caráter cruel ou infamante, proibida em qualquer caso a pena de morte".

A tolerância à aplicação de sanções pelos próprios grupos indígenas não exclui em absoluto, porém, a possibilidade de aplicação das sanções penais pelo Estado. Consequência disso são os recorrentes conflitos entre as normas jurídicas postas pelo Estado e as sanções aplicadas no âmbito das comunidades indígenas, tal como ocorreu no caso envolvendo o índio Denilson Trindade, analisado neste trabalho.

O caso do indígena Denilson evidencia claramente o conflito entre o sistema punitivo indígena e o ordenamento jurídico brasileiro, além da descomunal diferença entre as penalidades aplicáveis para a conduta praticada.

Reconheceu a Justiça brasileira, no caso em análise, a autonomia tribal, respeitando o julgamento da comunidade indígena, que foi realizado de acordo com os seus costumes e tradições, se abstendo o Estado de aplicar a legislação penal para um crime doloso contra a vida praticado dentro do território brasileiro.

In casu, a decisão do "tribunal" indígena traduz a percepção de justiça para aquela cultura e, ao revés, a punição do Estado brasileiro, da maneira convencional, poderia não atingir as finalidades da pena.

Diante disso, com um claro viés comunitarista e em consonância com as ideias do novo constitucionalismo latino-americano, a cultura e as crenças da comunidade indígena foram valorizadas e respeitadas, em detrimento da aplicação das normas convencionais do ordenamento brasileiro, em prol do ideal de justiça para a comunidade indígena.

Ante o exposto, conclui-se que o pensamento comunitarista e o novo constitucionalismo latino-americano têm o condão de conciliar o sistema punitivo indígena 
com o ordenamento jurídico brasileiro, além de evidenciarem a necessidade de análise de cada conflito de interesse de forma particular, para que seja possível alcançar o ideal de justiça para aquela comunidade específica diretamente atingida.

\section{REFERÊNCIAS}

ALMEIDA, Fábio Portela Lopes de Almeida. Os direitos fundamentais entre liberais e comunitaristas: um debate constitucional. Revista de Direito Constitucional e Internacional, vol. 59/2007, p. 86-130, abr./jun. 2007.

AVRITZER, Leonardo; et al. O constitucionalismo democrático latino-americano em debate: soberania, separação de poderes e sistema de direitos. 1 ed. Belo Horizonte: Autêntica, 2017.

BRASIL. Constituição da República Federativa do Brasil, de 05 de outubro de 1988. Diário Oficial da União, Brasília-DF, 1988. Disponível em: <http://www.planalto.gov.br/ccivil_03/constituicao/constituicao.htm>. Acesso em: 21 fev. 2021.

BRASIL. Decreto-lei n. 2.848, de 7 de dezembro de 1940. Código Penal. Diário Oficial da União, Brasília-DF, 31 de dezembro de 1940. Disponível em: < http://www.planalto.gov.br/ccivil_03/decreto-lei/del2848compilado.htm>. Acesso em: 21 fev. 2021.

BRASIL. Lei n. 6.001, de 19 de dezembro de 1973. Dispõe sobre o Estatuto do Índio. Diário Oficial da União, Brasília-DF, 19 de dezembro de 1973. Disponível em: < https://www.planalto.gov.br/ccivil_03/leis/16001.htm>. Acesso em: 24 mar. 2021.

CÂMERA, Juliana de Azevedo Santa Rosa Câmera. A sanção criminal no direito pena indígena: do pluralismo jurídico ao reconhecimento de regras consuetudinárias de resolução de conflitos penais. Revista Brasileira de Ciências Criminais, vol. 133/2017, p. 69-107, jul./2017.

CITTADINO, Gisele. Pluralismo, direito e justiça distributiva: elementos da filosofia constitucional contemporânea. $3^{\mathrm{a}}$ ed. Rio de Janeiro: Editora Lumen juris, 2004. Capítulos 2 e 3. p. $75-139$.

EStado PluRinacional DA BOlíVia. Constituición Política del Estado Plurinacional de Bolívia de 2009. Disponível em: < https://tcpbolivia.bo/tcp/sites//default/files/images/pdf/leyes/cpe/cpe.pdf $>$. Acesso em: 21 fev. 2021.

FILHO, Gabriel Barbosa Gomes de Oliveira. O Estado Plurinacional da Bolívia: as garantias fundamentais à autonomia e autogoverno das autoridades indígena originário campesinas. Dissertação (Mestrado). Universidade Federal Fluminense. Programa de pósgraduação stricto sensu em direito constitucional. Niterói, 2016. 
HESPANHA, Benedito. Justiça comunitarista, política e constituição. Revista de Direito Constitucional e Internacional, vol. 35/2001, p. 63-81, abr./jun. 2001.

LOPES, Ana Maria D'Ávila; UCHOA, Cibele Alexandre. A garantia do ne bis in ideme o reconhecimento dos direitos culturais dos indígenas. Revista Direito e Liberdade, Natal, v. 20, n. 2, p. 11-30, maio/ago. 2018. Quadrimestral.

PASTOR, Roberto Viciano; DALMAU, Rubén Martínez. El nuevo constitucionalismo latinoamericano: fundamentos para una construcción doctrinal. Revista General de Derecho Público Comparado, vol. 9, p. 1-24, 2011.

RIVA, Leura Dalla; NOVELLI, Rodrigo Fernando. O sistema punitivo do indígena no ordenamento jurídico brasileiro: a exceção ao monopólio estatal do poder de punir. Revista Jurídica Unigran. Dourados, vol. 19, n. 38, jul./dez. 2017. Disponível em: <https://www.unigran.br/dourados/revista_juridica/ed_anteriores/38/artigos/artigo10.pdf> Acesso em: 21 de fev. 2021.

RORAIMA, Tribunal de Justiça Do Estado de Roraima (Câmera única). Apelação Criminal n. 0090.10.000302-0. Apelante: Ministério Público do Estado de Roraima. Apelado: Denilson Trindade Douglas. Relator Desembargador: Mauro Campello. Boa Vista, RR, 18 de dezembro de 2015. Diário da Justiça Eletrônico, Boa Vista, RR, 17 de fevereiro de 2016. Disponível em: < http://jurisprudencia.tjrr.jus.br/juris/detalhes.xhtml?juris=17554>. Acesso em: 21 fev. 2021.

RORAIMA. Tribunal de Justiça do Estado de Roraima. Ação Penal n. 0090.10.000302-0. Autor: Ministério Público do Estado de Roraima. Réu: Denilson Trindade Douglas. Juiz de direito: Aluizio Ferreira Vieira. Bonfim, RR, 03 de setembro de 2013. Diário da Justiça Eletrônico, Boa Vista, RR, 05 de setembro de 2013. Disponível em: < http://diario.tjrr.jus.br/dpj/dpj-20130905.pdf>. Acesso em: 21 fev. 2021.

ROSAS, João Cardoso. Manual de Filosofia Política. 2 ed. Coimbra: Almedina, 2013.

ROTHENBURG, Walter Claudius. Índios e seus direitos constitucionais na democracia brasileira. Revista de Direito Constitucional e Internacional, vol. 60, p. 281-297, jul/set. 2007.

SANTOS, Boaventura de Sousa. A gramática do tempo: para uma nova cultura política. v. 4. São Paulo: Cortez, 2006. p. 433-470.

SANTOS, Fernando Nascimento dos. Responsabilidade penal do índio: insuficiência da dogmática e a necessidade de diálogo intercultural com os povos indígenas. Revista Brasileira de Ciências Criminais, vol. 142/2018, p. 17-46, abr./2018.

SCHMIDT, João Pedro. Comunidade e comunitarismo: considerações sobre a inovação da ordem sociopolítica. Ciências Sociais Unisinos, São Leopoldo, Vol. 47, n. 3, p. 300-313, Set./Dez. 2011. 
SCHMIDT, João Pedro; KIRCHHEIM, André. Políticas comunitárias no Brasil. Revista Jurídica da Presidência, v. 16, n. 108, p. 165-191, Fev./Mai. 2014.

SEGATO, Rita Laura. Que cada povo teça os fios da sua história: o pluralismo jurídico em diálogo didático com legisladores. Revista de Direito da Universidade de Brasília, vol. 1, n.1, jan./jun. 2014.

TAVARES, Felipe Cavaliere. O comunitarismo e seu ideal de justiça. Legis Augustus, Rio de Janeiro, v. 5, n.1, p. 31-44, jan./jun. 2014.

XIMENES, Julia Maurmann. Algumas reflexões sobre a incorporação do paradigma comunitarista na Constituição de 1988. Revista Sequência, n. 57, p. 47-66, dez. 2008.

WALKMER, Antonio Carlos. Pluralismo jurídico: fundamentos de uma nova cultura do direito. 4 Ed. São Paulo: Saraiva, 2015. 